\title{
Anaheim Meeting Covers Broad Range of Materials Advances
}

\section{Coverage Extends Beyond Electronic Materials Topics}

High temperature superconductors, magnetic materials, novel catalysts, geological materials, small clusters, and materials for aerospace applications - these topics added new dimensions to the technical program of the 1987 MRS Spring Meeting, held April 21-25 in Anaheim, California. Previous MRS Spring Meetings have provided extensive coverage of materials and processes for the semiconductor industry, and a number of symposia continued the substantial dialogue engendered by this far-reaching field. Building on the impetus fostered by these dialogues, this most recent meeting expanded the boundaries for interaction among scientists and researchers from different disciplines by providing a forum for these additional areas. More than 1,500 scientists from around the world participated in the 13 topical symposia.

Six symposia this year were new for MRS or hadn't been addressed at an MRS meeting within the past three to four years. Among them was the symposium on Permanent Magnet Materials, which provided an update of synthesis, intrinsic and extrinsic properties, microstructural modifications, and applications of both $\mathrm{Sm}-\mathrm{Co}$ and $\mathrm{Nd}-\mathrm{Fe}-\mathrm{B}$ permanent magnet materials.

The symposium on Materials for Aerospace Applications explored how super heat-resistant ceramics, siliconreinforced alloys, and erosion-resistant polymers will impact our lives beyond their uses in the space program. Complementing this symposium was the Wednesday evening Plenary Address by NASA Astronaut Bonnie J. Dunbar, who provided an inside look at her work as mission specialist on the 1985 West German Spacelab mission, during which 75 experiments in physiological sciences, materials processing, biology, and navigation were performed. She also provided insight into future materials needs for space station development and experimentation, and called upon materials researchers in industry and universities to become more involved in the space program for the benefit of advancing the knowledge and application of materials.

The classical synergism of interdisciplinary research that occurs at MRS meetings was well represented in the symposium on Geological Materials: Silicate Melts and Glasses. This symposium provided a new forum for discussion between both geologists and materials scientists with mutual interests in how materials research may help predict earthquakes, locate oil reserves, and further the study of properties of silicate melts under extreme pressure.

Seven symposia conducted at the 1987 Spring Meeting continued the dialogue of predecessor symposia at previous Fall or Spring Meetings. The importance of these continuing discussions was clearly evidenced at the symposium on Heteroepitaxy on Silicon, in which the attendance was double that of last year's symposium. The symposium on Rapid Thermal Processing of Electronic Materials featured both intense oral paper sessions as well as a special panel discussion between vendors and users of RTP equipment.

It is difficult to underestimate the excitement generated by the "late-news" symposium on High Temperature Superconductors. What started. as a small one-day symposium focusing on the work of 15 noted researchers grew to a long two-day event featuring 80 researchers who were changing and updating their research results until the minute of their presentations at the symposium.

Among the notable speakers at this symposium were J.G. Bednorz (IBM Zurich), S. Tanaka (University of Tokyo), and C.W. Chu (University of Houston), plus leading researchers from AT\&T Bell Laboratories, Stanford University, Ames Laboratory, Naval Research Laboratory, University of California, KFZ Karlsruhe (West Germany), and elsewhere. Presentations spanned electrical and electronic proper- ties; Josephson effects; thin film, SQUID, and coil preparation; and systems such as $\mathrm{YBa}_{2} \mathrm{Cu}_{3} \mathrm{O}_{9-\mathrm{y}}, \mathrm{ABa}_{2} \mathrm{Cu}_{3} \mathrm{O}_{6-\mathrm{x}}, \mathrm{YBa}_{2-\mathrm{x}} \mathrm{Sr}_{\mathrm{x}} \mathrm{Cu}_{3} \mathrm{O}_{y}$, $\mathrm{La}_{1.85} \mathrm{Sr}_{0.15} \mathrm{CuO}_{4}$, and many more. Attendance at the symposium was never less than 500 , even during the presentations conducted near midnight on Thursday, and it often peaked at 1,000.

The overall technical program was enhanced by a parallel equipment exhibit and extensive short course program, both focusing on the latest materials research techniques and devices and both complementing the symposia. Adding these features to the carefully planned logistics and superior technical quality of the symposia produced a highly informative and rewarding scientific meeting.

The following reports provide a closer glimpse at some of the multidisciplinary research covered at this meeting. For more detail on specific symposium activities, consult the publications referenced at the end of each of the following symposium summaries.

\section{Heteroepitaxy on Silicon Technology (Symposium A)}

Symposium Organizers: John C.C. Fan (Kopin Corporation), Julia M. Phillips

(AT\&T Bell Laboratories), and B-Y. Tsaur (MIT Lincoln Laboratory).

This symposium had more than twice as many papers as last year, with 50 talks and over 20 poster presentations. Approxi-

Continued

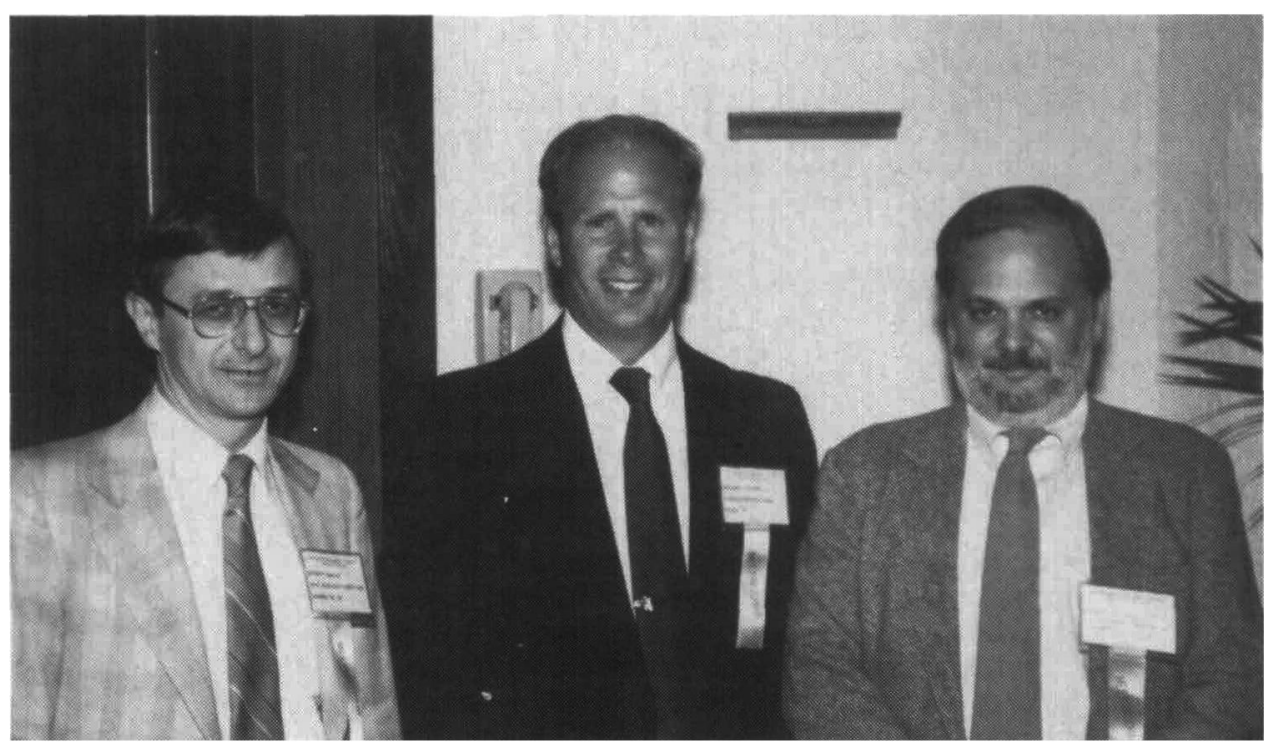

1987 Spring Meeting Chairs (left to right): G.K. Hubler, G.L. Olson, and R.R. Chianelli. 


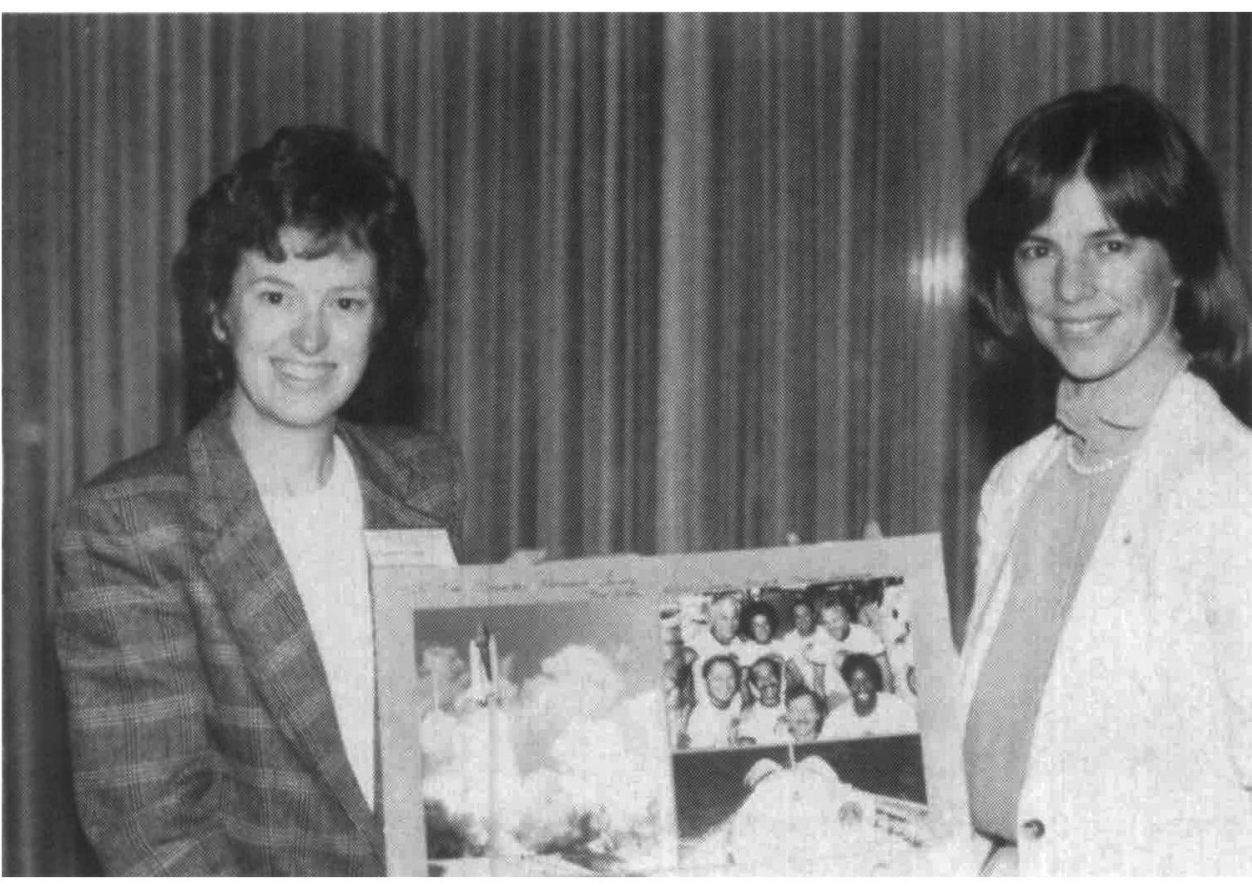

MRS President Kathleen C. Taylor (left) presents a gift to Dr. Bonnie J. Dunbar, Plenary Speaker and NASA Astronaut.

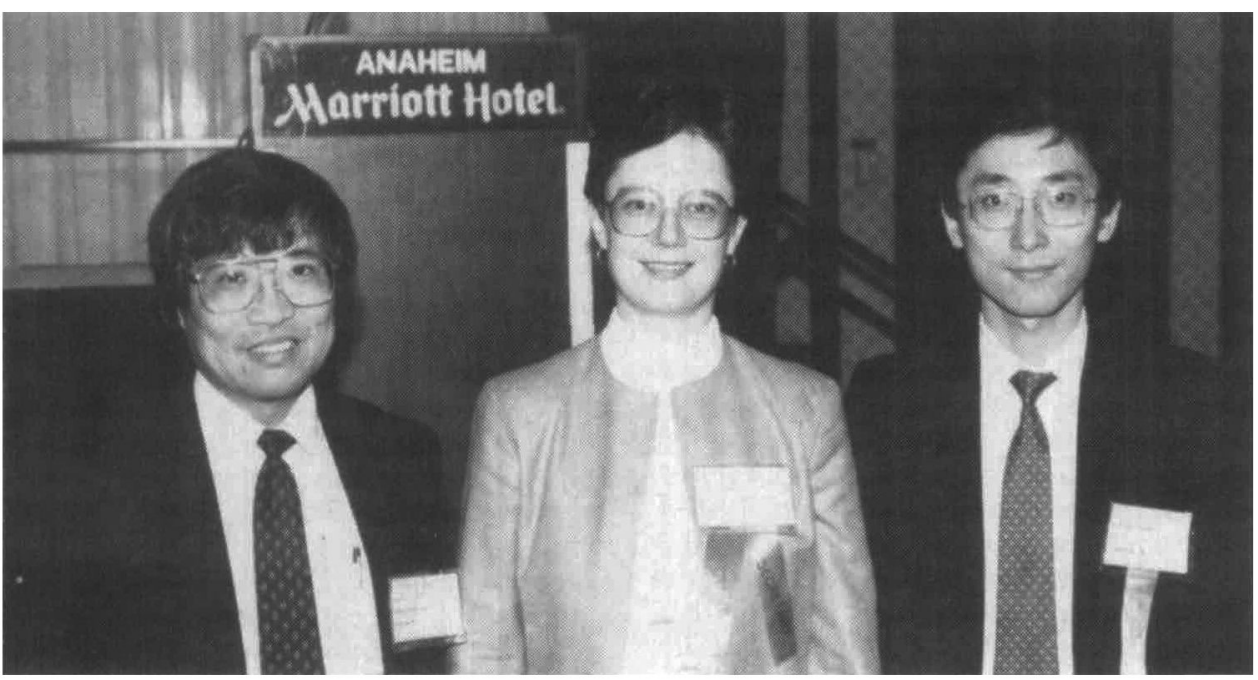

Symposium A Organizers (left to right): J.C.C. Fan, J.M. Phillips, and B.-Y. Tsaur.

mately half of the symposium was devoted to the rapidly emerging area of GaAs growth on Si. The remaining presentations discussed progress in group IV heteroepitaxy (primarily Si-Ge heterostructures), epitaxial approaches to SOI (semiconductor-on-insulator) technology, and heteroepitaxial metal-Si structures.

The symposium began with a plenary session during which J.S. Harris (Stanford) discussed the issues involved in the nucleation and growth of GaAs on $\mathrm{Si}$, and D.W. Shaw (Texas Instruments) addressed the progress on and potential applications of these GaAs-Si heterostructures. The possi- made in bulk GaAs. The performance of minority carrier devices, on the other hand, still leaves room for improvement.

The panel discussion was chaired by $\mathrm{H}$. Kroemer (University of California, Santa Barbara). Panelists were $\mathrm{K}$. Ishida (Optoelectronics Joint Research Laboratory), H. Morkoc (University of Illinois), E. Weber (University of California, Berkeley), D. Shaw, and J. Harris. The discussion centered on the problems which must be surmounted before $\mathrm{GaAs}$ on $\mathrm{Si}$ can be considered a viable technology. Agreement emerged that most, if not all, of the difficulties can be traced to the dislocations which arise in the GaAs layer as a result of the large $(\sim 4 \%)$ lattice mismatch between $\mathrm{GaAs}$ and $\mathrm{Si}$. This may be exacerbated by the substantial thermal mismatch between the two materials. More fundamental work is needed to understand the initial nucleation and growth of the epitaxial GaAs layer. Such understanding may eventually allow the dislocations to be confined to the interface where they are not expected to interfere with device performance. It is thought that the future of $\mathrm{GaAs}$ on $\mathrm{Si}$ is bright once the dislocation problem is overcome.

There has been considerable progress over the last several years in the heteroepitaxial growth of strained-layer structures of $\mathrm{Si}, \mathrm{Ge}$, and the alloys of these two elemental semiconductors. In these materials, the combination of strain and artificial layer periodicity can yield properties beyond those found in the individual semiconductors. Materials and device characteristics of these layers, as well as theoretical studies of their properties, were the subject of a review by J.C. Bean (AT\&T Bell Laboratories) and several other talks and posters. One of the most impressive recent achievements is the growth of atomically layered $\mathrm{Ge}-\mathrm{Si}$ structures, which display remarkably different energy level structures depending on the number of monolayers in the individual layers. The energy level structure also strongly depends on whether the layers themselves are random or ordered.

Among the heteroepitaxial approaches to SOI, the most popular seems to be the use of an alkaline earth fluoride such as $\mathrm{CaF}_{2}$ as the insulating layer. These materials have a number of advantages, such as the large variability in their lattice constant and their ability to act as a strain relief layer in a heterostructure. Progress in the epitaxial growth of several different semiconductors on fluoride layers on $\mathrm{Si}$ was reviewed by $T$. Asano (Tokyo Institute of Technology). Devices which have been fabricated in such layers were reviewed by $\mathrm{H}$. Onoda (OKI).

Epitaxial metal silicides, especially $\mathrm{CoSi}_{2}$ and $\mathrm{NiSi}_{2}$, have been the subject of intensive investigation for several years. The

Continued 
possibilities of fabricating metal-base and permeable-base transistors using these materials have been particularly tantalizing. There has, however, been considerable disagreement among the various workers in the field regarding fundamental aspects of the growth and properties of $\mathrm{CoSi}_{2}-\mathrm{Si}$ structures. This was the subject of animated discussion during this session and at the poster session. A consensus seems to be emerging regarding these questions, and all devices fabricated to date in this system are almost certainly permeablebase transistors. It remains to be seen whether a true metal-base transistor with desirable operating characteristics can be fabricated using epitaxial silicides and $\mathrm{Si}$.

In all the systems discussed at this symposium, considerable emphasis was placed on the importance of the initial stages of epitaxial growth to the final properties of the heterostructures. This issue was addressed in detail by Symposium D. Many attendees found that the complementary treatments of these two symposia were particularly beneficial in obtaining an overview of many important issues in heteroepitaxial growth.

Symposium Support: Air Force Office of Scientific Research (K.J. Malloy and G. Witt), Kopin Corporation.

Proceedings: Volume 91 of the Materials $R e$ search Society Symposia Proceedings series.

\section{Rapid Thermal Processing of Electronic Materials (Symposium B)}

Symposium Organizers: Syd R. Wilson

(Motorola, Inc.), Ron Powell (Varian Associates), and D. Eirug Davies (EOARD).

The first symposium was held during the 1985 MRS Fall Meeting in Boston. It was devoted exclusively to rapid thermal processing (RTP), i.e., rapid annealing performed with broad beam energy sources such as quartz halogen or arc lamps in which heating/cooling times are 1-100 s. Recognizing the continued need for such a forum, the present symposium was organized to provide a topical treatment of developments in RTP of electronic materials and devices. This well-attended meeting brought together approximately 200 scientists and engineers. Strong participation from Japanese and European researchers was especially gratifying and contributed to the international flavor of the symposium. Over 60 contributed papers and 7 invited papers were presented on a wide range of topics:

- Ion implantation, dopant activation and diffusion

- Dielectrics, rapid thermal oxidation and nitridation

- Silicides and metals

- Devices and circuits

- Recent developments in RTP equipment

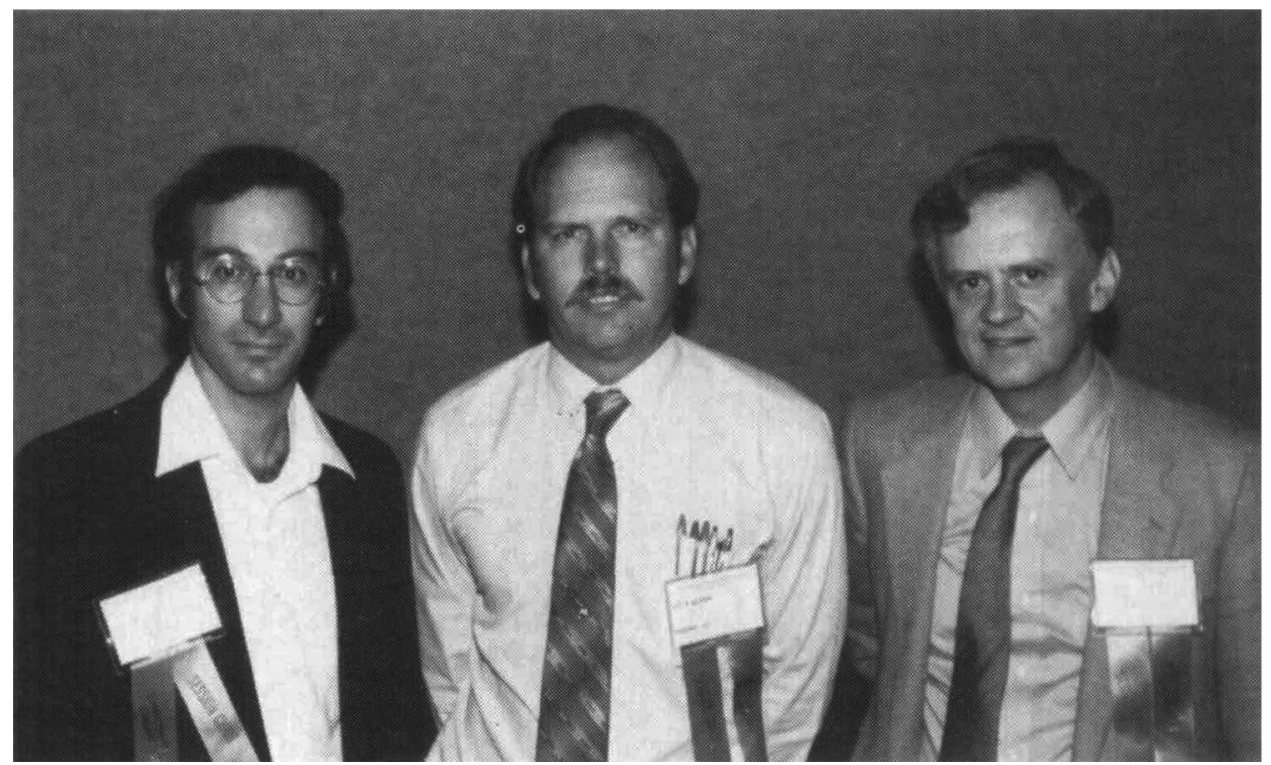

Symposium B Organizers (left to right): R. Powell, S.R. Wilson, and D.E. Davies.

- New applications of RTP

- Defects and microstructure

- Compound semiconductors

Both formal and informal channels of communication were provided for attendees. An evening social hour was followed by a lively panel discussion in which both vendors and users of RTP equipment discussed issues of general interest. Along with moderator R. Powell, six panelists (J. Gelpey, D. Hodul, A. Kermani, J. Nulman, and S. Shatas) and members of the audience fielded such loaded questions as "When will RTP move into production in a big way?" and "Why can't vendors use the same type of wafer temperature measurement scheme?" While disagreeing on a number of issues, the panelists did agree that the most exciting future applications for RTP appear to be in in situ or integrated processing - e.g., the combination of RTP and CVD being pursued by J. Gibbons and co-workers at Stanford University to grow superlattices by rapidly changing substrate temperature, thereby switching surface driven reactions off and on.

It was clear from the large number of papers on applications of RTP to III-V compound semiconductors and modulation doped GaAs devices such as superlattices and MODFETs that this field is of great interest. Work on III-V materials accounted for nearly one third of all papers presented at the symposium. Moreover, the damage produced in sensitive III- $\mathrm{V}$ materials by RTP is also starting to get the attention it deserves. For example, several Japanese authors discussed the generation of deep level EL2 traps in GaAs substrates and epilayers induced by strain during rapid heating or cooling.

In silicon technology, processing of MOS devices still appears to be the dominant ap- plication for RTP; however, several papers on the advantageous use of RTP in bipolar IC technology suggest increased activity in this area - particularly as the speed of bipolar devices continues to be pushed ever higher. Another topic that drew interest at the symposium was the continued development of rapid thermal drive-in doping to replace or augment conventional ion implantation. This scheme appears applicable to both bipolar and MOS shallow junction formation and is very promising for doping compound semiconductors as well.

Overall, Symposium B was a highly successful technical meeting which provided a common focus for many interrelated materials, device, and process issues and which helped foster better communication between vendors and users of RTP equipment.

Symposium Support: Eaton Corporation, Peak Systems, Inc., Process Products Corp., Varian Associates, AG Associates, Motorola, Inc., Tamarack Scientific Company.

Proceedings: Volume 92 of the Materials Research Society Symposia Proceedings series.

\section{Materials Modification and Growth Using lon Beams (Symposium C)}

Symposium Organizers: Ursula Gibson (University of Arizona), Peter P. Pronko (Universal Energy Systems), and Alice E. White. (AT\&T Bell Laboratories).

In organizing Symposium $C$ this year, we tried to bring together investigators of low, intermediate, and high energy ionactivated processes for materials modification. Walter Brown started off the first of nine sessions with an entertaining and educational perspective on the relationships

Continued 


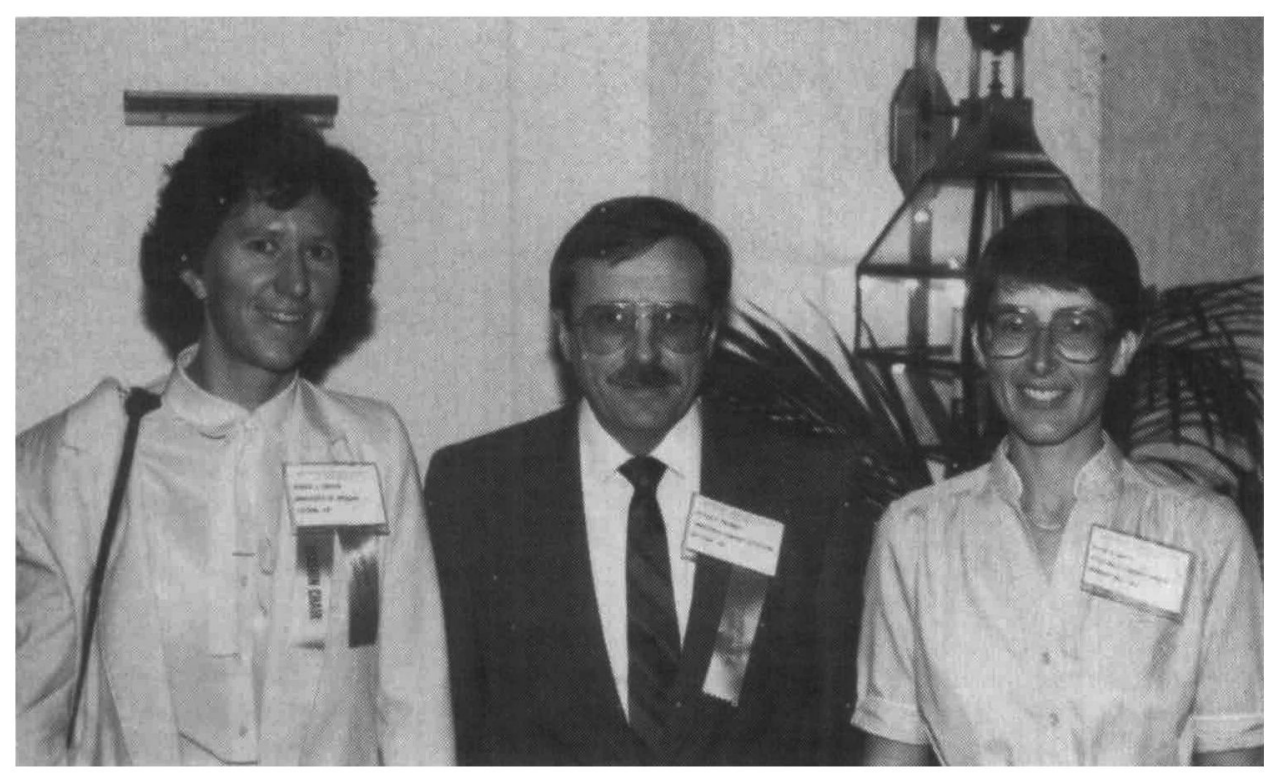

Symposium C Organizers (left to right): U. Gibson, P.P. Pronko, and A.E. White.

among the many diverse topics which followed. Tuesday's sessions were devoted to "fundamental beam-solid interactions" which ranged from the intriguing observation of a Ge layer forming behind the oxidation front in Ge-implanted silicon to studies of ion-beam-enhanced grain growth. Beer and German-style snacks helped the flow of information at the evening poster session, which included late-breaking news about strain measurements on ion-implanted $\mathrm{Si}$ and a new technique for projection ion beam lithography which takes advantage of the differences in optical reflectivity between amorphous and crystalline silicon.

Wednesday morning was devoted to a lively and well-attended session on Siliconon-Insulator (SOI) by high dose ion implantation. This technology is clearly still in the running! Of particular interest was the confirmation of the presence of oxygen "bubbles" in silicon samples which had experienced a high dose rate implantation of oxygen. This was a subject of some controversy during Symposium A at the 1986 MRS Fall Meeting. Both afternoon sessions covered ion mixing. The first was limited to mixing of semiconductor superlattices and the two invited speakers provided a very comprehensive overview of the status of the field for both $\mathrm{GaAs} / \mathrm{AlGaAs}$ and $\mathrm{GaAs} /$ InGaAs superlattices. This moved fairly naturally into a session on general ion beam mixing for compound and alloy formation.

Thursday's sessions covered the use of ion beams in the production of various types of coatings, particularly those for optical and tribological applications. Some of the processes described used much lower energies than conventional implantation but achieved comparable changes in stoi- chiometry, since the beam was used during the growth of the materials by vapor deposition. Various theoretical models for the effect of thin film structure of these low energy processes were described. Corrosion and wear reduction properties of a number of materials were also discussed.

At the week's end, we felt as if we had not promoted as much interaction among the different interest groups as we had hoped. This was due, in part, to being somewhat overshadowed by the high $T_{c}$ superconductivity session. Nonetheless, attendance was healthy, the discussions were lively, and everyone came away with something new to ponder.

Symposium Support: Air Force Office of Scientific Research (J.W. Hager), Defense Advanced Research Projects Agency (P.A. Parrish), Office of Naval Research (K.B. Hathaway and $L$. Corporation, Ion Tech, Inc., National Electrostatics Corporation, Optical Coating Laboratory, Inc.

Proceedings: Volume 93 of the Materials $R e$ search Society Symposia Proceedings series.

\section{Initial Stages of Epitaxial Growth (Symposium D)}

\section{Symposium Organizers: Robert Hull} (Hewlett-Packard Laboratories), J. Murray Gibson (AT\&T Bell Laboratories), and David A. Smith (IBM Thomas J. Watson Research Center).

This symposium was designed to bring together scientists interested in the fundamentals of nucleation and growth of epitaxial layers and those concerned with the use of such layers for either scientific or technological study. Judging by the number and quality of contributions and the high attendance, this was very successful. The opening session concentrated on the Cooper), Eaton Corporation, General lonex

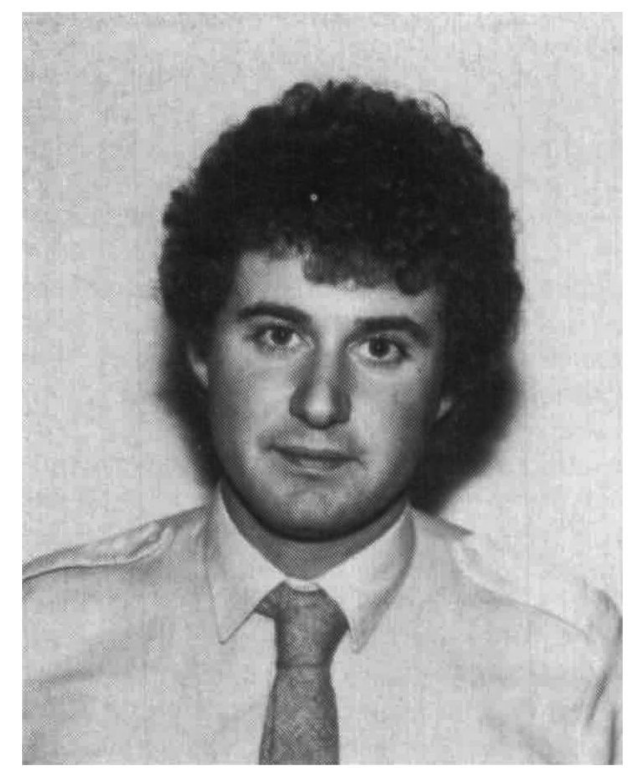

Symposium D Organizer: R. Hull.

exciting area of in situ monitoring of epitaxial growth, led off by J. Venables (Sussex/ Arizona State) who discussed nucleation and growth observed directly by scanning electron microscopy. The session also included talks on scanning tunneling microscopy, transmission electron microscopy, field-ion microscopy, Raman scattering (R.J. Nemanich, North Carolina State), photoemission and ellipsometry.

Theoretical discussions of growth, concentrating on the effect of misfit stress, were led off by J. Cahn (National Bureau of Standards) and included weakly interacting systems (S. Dregia, Carnegie Mellon) and critical thickness considerations. Experimental data followed, including the effects of misfit dislocations on film morphology (D. Cherns, Bristol), critical thickness studies with reflection electron diffraction (F.J. Grunthaner, Jet Propulsion Laboratory), transmission electron mi-

Continued

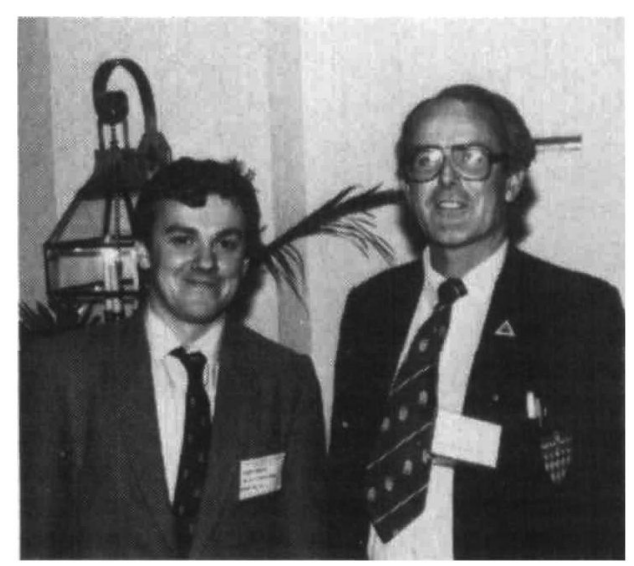

Symposium D Organizers (left to right): J.M. Gibson and D.A. Smith. 
croscopy, and the effect of large misfit on epitaxy.

F. Himpsel (IBM) led off a session on the effects of surface structure on epitaxy with the first of two talks on $\mathrm{CaF}_{2}$ on $\mathrm{Si}$. As on $\mathrm{Si}$ and its relevance to $\mathrm{GaAs} / \mathrm{Si}$ growth was discussed by J. Patel (AT\&T Bell Laboratories) and others. H. Gossman (AT\&T) continued with studies of group IV elements on $\mathrm{Si}$, where effects of surface relaxation are clear. Others showed examples where surface structure affects growth, e.g., Si on $\mathrm{CoSi}_{2}$.

Molecular dynamics modeling of semiconductor growth presented by M.H. Grabow (AT\&T) led the last oral session on nucleation and growth fundamentals in which F.A. Ponce (Xerox) showed high resolution electron microscopy of $\mathrm{GaAs}$ on $\mathrm{Si}$ and G.B. Stringfellow (University of Utah) discussed III-V epitaxy by OMVPE. Symposium Support: Army Research Office (J.M. Zavada), Office of Naval Research (K.B. Hathaway).

Proceedings: Volume 94 of the Materials Research Society Symposia Proceedings series.

\section{Amorphous Silicon Semiconductors - Pure and Hydrogenated (Symposium E)}

Symposium Organizers: $D$. Adler

(Massachusetts Institute of Technology),

Y. Hamakawa (Osaka University),

A. Madan (Glasstech Solar, Inc.), and M. Thompson (Xerox PARC).

The symposium, which focused on key issues in the science and technology of the novel amorphous tetrahedrally bonded materials systems, featured a packed audience and enthusiastic discussions. Detailed papers were presented on the electronic structure of a-Si:H and related alloys. Electronic and optoelectronic properties in a-Si material are characterized by a large density of the midgap states originated from the unpassivated dangling bonds or defects in the amorphous network. Recently, knowledge of electronic and optical processes of the midgap states have been clarified with emphasis not only on the energy locations of $\mathrm{D}_{1}, \mathrm{D}_{2}$ and $\mathrm{D}^{*}$ states (or $\mathrm{D}^{+}, \mathrm{D}^{\circ}$, $D$, and $U_{\text {eff }}$ but also on their distributions with the help of characterization techniques such as DLTS (Deep Level Transient Spectroscopy), CPM (Constant Photocurrent Method), CTS (Current Transient Spectroscopy), MPS (Modulated Photocurrent Spectroscopy), etc.

However, new questions arise about the microstructure and source of the dangling bond states related to the hydrogen diffusion, Si-Si bond breaking mechanism under the photo-, stress-, and thermal-energy perturbations. Hydrogen diffusion and the effect of annealing in the a-Si system are being intensively studied. Carrier dynamics correlated with localized gap states in undoped and doped a-Si: $\mathrm{H}$ are also being studied.

The panel discussion, an innovative event for this symposium, reviewed and discussed present knowledge for various features of the DOS spectra. Four panelists reviewed "Microstructure and Hydrogen Diffusion," "Gap State Spectroscopies and Characterizations," "Impurity Related Processes," and "Stability on Photon Irradiation and Other Energy Perturbation."

It was evident from the many papers presented that there are still many issues to be solved on film growth kinetics and atomic structure of a-Si alloys with regard to electronic and optical properties. Film quality improvement and growth rate are also key elements for commercialization.

Plasma chemistry in gas phase reaction, effect of hydrogen dilution and related surface reaction, and correlation of hydrogen with dopants were discussed. Local structure in hydrogenated amorphous silicon network with and without substitutional impurities has been investigated by NMR, ENDOR, and Coherent Anti-Stokes Raman Spectroscopy. New deposition techniques such as HR-CVD (Hydrogen Radical Enhanced CVD), ECR-CVD (Electron Cyclotron Resonance CVD), and CTL-CVD (Catalytic CVD) were reported.

Noticeable progress in the amorphous semiconductor field has occurred in the development of the amorphous mixed alloys such as a-SiC, a-SiN, a-SiGe, A-SiN, and microcrystalline materials. All these materials have considerably good valence electron controllability by doping by substitutional impurity. Substitutional and interstitial doping of a-SiN are being systematically investigated over a wide range of ammonia/silane mixtures. Regarding aSiGe alloys, reports on the effect of hydrogen contents and role of fluorine on the film quality were highlights in the session. For solar cell, photoreceptor, and other optoelectronic functional devices, a-SiC alloy is of great interest. Comparative studies of structure and hydrogen incorporations in a-SiC have been done by several groups.

Current topics on the interface, heterojunctions, and superlattices were discussed. The review paper pointed out that many issues remain to be resolved with regard to interface states, the midgap states, and also Schottky barrier contact in metal/ a-Si alloys. Heterojunctions in a-SiC/a-Si, a-Si/a-SiGe, and a-Si/a-SiN are of great interest and important for device applications. A remarkable recent trend is that the superlattices in a-Si alloy system are becoming useful functional elements in device applications, such as efficient wide gap windows in solar cells, carrier injection electrodes, and a new type of Schottky contact. A new fabrication technique of aSiC/a-Si superlattice by PP\&P (Pulsed Plasma and Photo) CVD was postulated.

Many papers were devoted to amorphous silicon solar cells, one of the largest application areas already representing over one third of the world photovoltaic market. Because of their potential importance in the module efficiency improvement for power applications, $R \& D$ has centered on the stacked solar cells using various bandgap materials such as a-Si alloys and polycrystalline thin films. Device physics considerations, optimum design concepts, material options for multijunction stacks, cell fabrication technologies, and also pho-

Continued

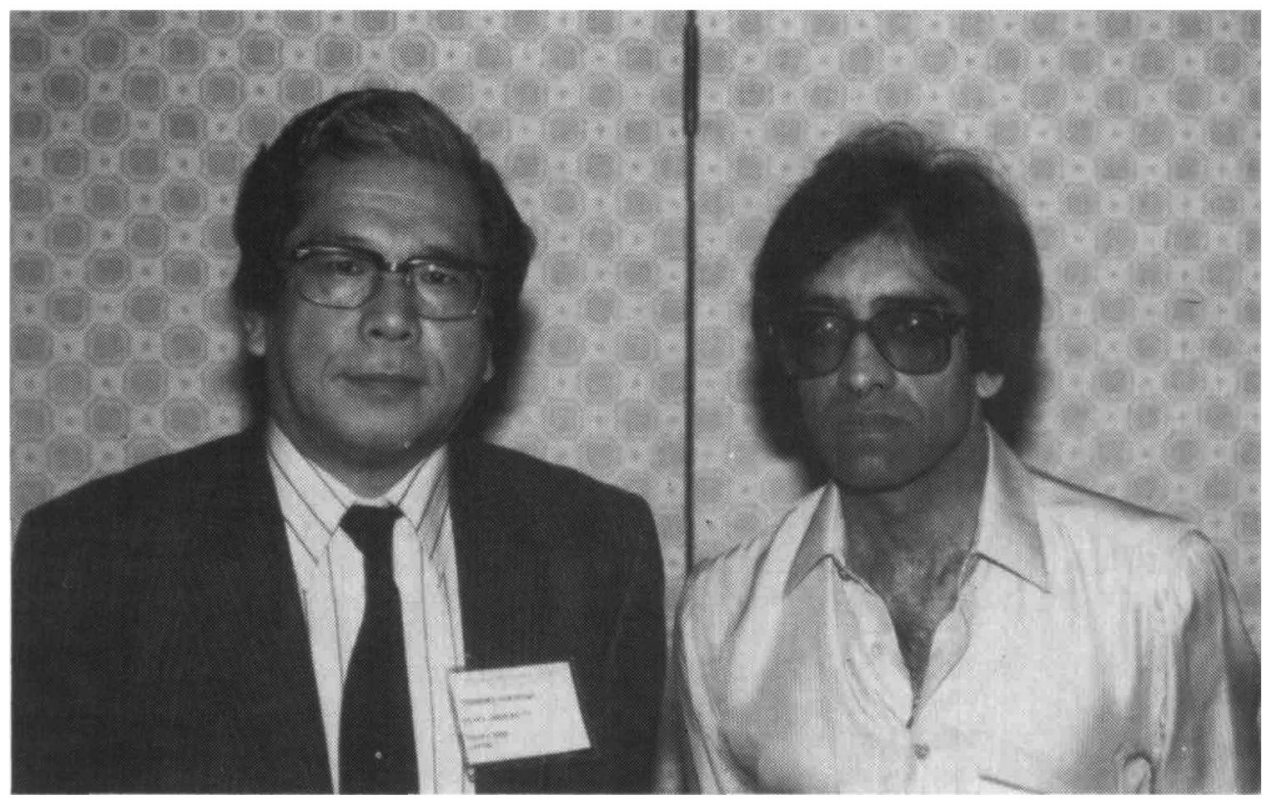

Symposium E Organizers (left to right): Y. Hamakawa and A. Madan. (Not shown, M. Thompson) 
tovoltaic system operation conditioning were discussed for two-terminal and fourterminal stacked solar cells. Some new technologies for enhancing efficiency, such as rough TCO contact, a bottom side barrier layer, and buffer layer in the stacked interfaces, were reported.

Light-induced effects in a-Si and the stability of a-Si solar cells are important issues in the development of photovoltaics. A fundamental topic is the origin of the lightinduced effect; in the past few years investigations have increased understanding of the electronic processes by light soaking and thermal annealing treatment. However, these effects involve the creation of deep metastable defects $D^{*}$ states after carrier recombination. Moreover, $D^{*}$ are also very sensitive to the quality of i-layer film which is basically related to the hydrogen content and nature of the amorphous network structure. Some new results on changes of IR vibrational absorption by light-soaking, light induced changes in the carrier drift mobility in a-Si:H, and also their thermal annealing behaviors were presented.

Thin film transistors (TFTs) are another extremely active field using a-Si technology devices. An advantage of uniform thin film deposition on large area foreign substrates in $\mathrm{a}-\mathrm{Si}: \mathrm{H}$ is fully utilized in the development of integrated TFTs and TFDs (Thin Film Diodes). A series of technical issues from device fabrication technologies, dynamic characteristics to application systems were reported. In material processing in this field, plasma-deposited a-Si:H, a$\mathrm{SiN}_{\mathrm{x}}$, low temperature thermal oxidation of silicon dioxide, and contact metallization effects were topical issues. A new type of linear imaging sensor with 2,560 picture elements 8.5 inches in length ( 300 bits inch) has been developed by an integration of a PD (photodiode) TFT with multiplex circuit on a glass substrate. Regarding LC display devices, a full color TV picture quality comparable to CRT was realized by using integrated TFTs having $408 \times 640 \times 3$ pixel elements with adequate uniformity and stability.

Photoreceptors and other optoelectronic device applications were also the subjects of one session. Using wide area uniform deposition and carrier blocking layers has helped advance the development of electrophotographic receptors and other optoelectronic devices. Although understanding of the operation of these photoreceptors has progressed, several issues remain to be clarified. Much attention and discussion focused on material combinations of back blocking layers by $p / i, n / i$, and heavily boron doped microcrystalline $\mathrm{Si}$, etc. A high deposition rate technology of thick a-Si:H films for the photoreceptor production purpose was also demonstrated and its properties with response

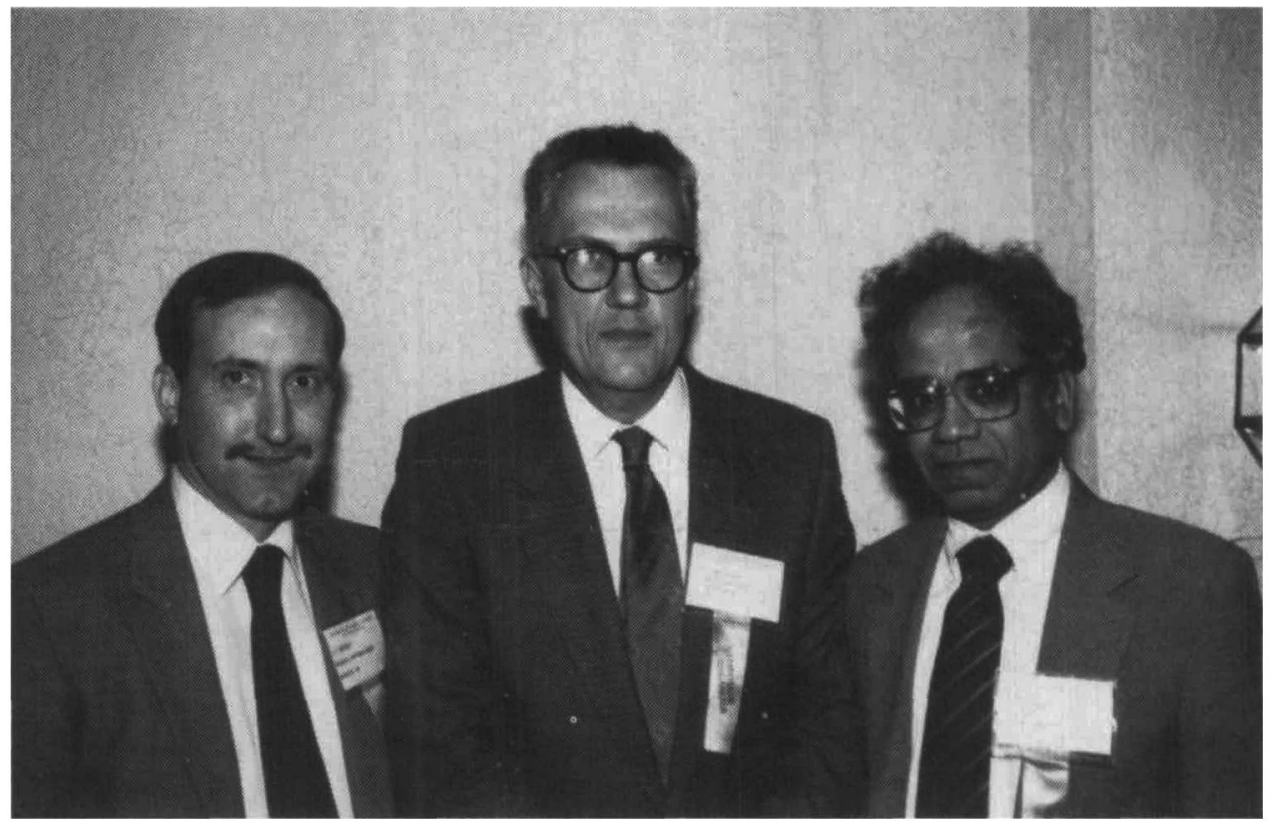

Symposium F Organizers (left to right): J.F. Herbst, N.C. Koon, and S.G. Sankar.

time were discussed.

In the miscellaneous device session, a wide variety of new functional elements were proposed; for example, an artificial neural network using binary synaptic connections based on a-Si memory switching, and a quantum effect device using metalnonmetal transition, etc. Among these, studies to develop visible LEDs in an a-SiC $p-i-n$ junction and to improve brightness by an efficient carrier injection with heterojunction gathered much attention. An innovative application field might be an OE-IC (optoelectronic integrated circuit) combined with a-Si alloy photosensors. A high speed a-Si p-i-n diode is also of great interest for practical applications.

Symposium Support: Amoco, ARCO Solar, Fuji-Xerox, Glasstech Solar, Inc. (GSI), IBM, Matsushita, SERI, Solarex, Sumitomo, 3M Company, Xerox.

Proceedings: Volume 95 of the Materials Research Society Symposia Proceedings series.

\section{Permanent Magnet Materials (Symposium F)}

Symposium Organizers: S.G. Sankar

(Carnegie Mellon University), J.F. Herbst (GM Research Laboratories), and N.C.

Koon (Naval Research Laboratory).

This symposium, held for the first time at the 1987 MRS Spring Meeting, focused on the synthesis, intrinsic and extrinsic properties, microstructural modifications, and applications of the traditional Sm-Co and novel $\mathrm{Nd}-\mathrm{Fe}-\mathrm{B}$ permanent magnet materials. Eight invited talks and 17 contributed papers were presented in four topical sessions. The purpose of the symposium was to provide a forum for experts in permanent magnet materials from around the world to assess the state-of-the- art and to outline the future trends in this interdisciplinary subject.

Several synthetic and materials processing techniques were discussed during the symposium. They included the synthesis of Nd-Fe-B and related alloys in the form of single crystals (B.N. Das and N.C. Koon), thin films (J. Zasadzinski et al.), rapidly solidified materials (F.E. Pinkerton and R.K. Mishra), and the use of liquid dynamic compaction (M.K. Veistinen et al.). All talks highlighted the unique advantages associated with each of these techniques. For example, single crystals were grown to determine the anisotropy constants of $\mathrm{Er}_{0.2} \mathrm{Y}_{0.8} \mathrm{Fe}_{14} \mathrm{~B}$ alloy (reviewed in an invited talk by C.M. Williams), which enabled evaluating the crystal field parameters of Er ion in the tetragonal structure. The thin films examined by Zasadzinski et al. showed that these alloys exhibit large polar Kerr rotations and respectable coercive fields, thus opening up new opportunities for their potential applications in magneto-optical devices.

In his invited talk, Pinkerton discussed the initial magnetization and demagnetization behavior of melt-spun ribbons, hot pressed magnets and die upset magnets and showed that the results are consistent with domain wall pinning at grain boundary phases as the dominant coercivity mechanism. Mishra presented the microstructural features of these materials and showed the correlation between the differences in the hard magnetic properties of the three classes of magnets with the differences in the distribution of $\mathrm{Nd}_{2} \mathrm{Fe}_{14} \mathrm{~B}$ crystallites as well as the pinning sites. Veistinen described the properties of NdFe-B magnets prepared by liquid dynamic

Continued 
compaction and said his team obtained an intrinsic coercivity of $7,500 \mathrm{Oe}$ for thick (>7 mm) samples.

The intrinsic properties of several rare earth alloys were discussed in two invited talks by K.H.J. Buschow and by W.E. Wallace et al. Buschow discussed the physical properties of $\mathrm{R}_{2} \mathrm{Fe}_{14} \mathrm{~B}$ alloys modified by substituting other elements for $\mathrm{R}, \mathrm{Fe}$ and $B$. He also described the preparation and magnetic properties of novel ternary intermetallics crystallized from the amorphous state, enumerating the advantages of this synthesis approach as a good research tool for the future discovery of permanent magnet materials. Wallace discussed the modification in the magnetic properties of . $\mathrm{Nd}_{2} \mathrm{Fe}_{14} \mathrm{~B}$ by substitutions with $\mathrm{Co}, \mathrm{Mn}, \mathrm{Si}$, $\mathrm{C}$, etc. He also discussed the chemistry of the intergranular phase in these alloys as revealed by Auger electron spectroscopy. He further described the significant enhancement in the anisotropy when $\mathrm{Zr}$ is introduced into the $\mathrm{R}_{2} \mathrm{Co}_{17}$ alloys.

F. Pourarian described the spin reorientation phenomena in $\mathrm{Nd}_{(2-x)} \operatorname{Pr}_{x} \mathrm{Co}_{14} \mathrm{~B}$ systems and in a separate paper alluded to the potential use of hydrogen in modifying the intrinsic magnetic properties of $\mathrm{R}-\mathrm{Fe}-\mathrm{B}$ alloys and the use of hydrogenation as a technological tool in powder decrepitation to fabricate magnets.

M.H. Ghandehari described the use of $\mathrm{Dy}_{2} \mathrm{O}_{3}$ as a sintering aid to obtain high coercivity. Several authors discussed the improved temperature characteristics and/ or fabrication of inexpensive misch metalFe-B magnets (B.M. Ma, R. Ramesh, J.K. Chen, Y. Xiao et al., and C.J. Willman). In an invited talk, M. Sagawa and S. Hirosawa described some new ideas about the magnetic hardening mechanism in sintered Nd-Fe-B magnets. J. Fidler discussed an analytical electron microscopy study on high and low coercivity $\mathrm{Sm}_{2} \mathrm{Co}_{17}$ magnets. The origin of spin reorientation phenomena in some 2:14:1 alloys was described by E.B. Boltich on the basis of a crystal field model. W.J. James described the power and utility of neutron diffraction techniques to unravel the magnetic and crystallographic structure of rare earth intermetallic alloys.

Three excellent invited papers dealt with the design considerations of permanent magnet structures. K. Halbach discussed the merits of using permanent magnet materials in combination with an electromagnet and showed how the peak field of the latter can reach - and sometimes surpass - that of a permanent magnet system. H.A. Leupold et al. and J. Chavanne et al. discussed several novel designs for device fabrication. J.R. Cost et al. described the effects of radiation on the stability of several commercial Sm-Co and Nd-Fe-B magnets. L.E. Crooks et al. discussed the use of permanent magnets in low field magnetic resonance imaging instruments. Symposium Support: Army Research Office, Air Force Office of Scientific Research, Advanced Materials Corporation.

Proceedings: Volume 96 of the Materials Research Society Symposia Proceedings series.

\section{Novel Refractory Semiconductors (Symposium I)}

Symposium Organizers: T.L. Aselage

(Sandia National Laboratories), David

Emin (Sandia National Laboratories), and Charles Wood (Jet Propulsion Laboratory).

This symposium principally addressed four classes of materials: boron-rich icosahedral solids, silicon-carbide, diamond, and the rare earth chalcogenides. There are qualitative differences in the major thrusts of the reported research in each of these areas.

The icosahedral boron-rich solids are refractory materials based on boron-rich icosahedral structural units. Current interest centers on understanding the distinctive transport properties of these solids. The electronic transport in the boron carbides occurs by the hopping of pairs of electrons (bipolarons) between boron-rich icosahedra. In addition, despite the very small structural changes which accompany changes in the carbon concentration of the boron carbides, the thermal conductivity changes from being crystal-like to glasslike with a change of carbon concentration. Their low thermal conductivities, anomalously large thermoelectric coefficients, and refractory nature make the boron car-

Continued

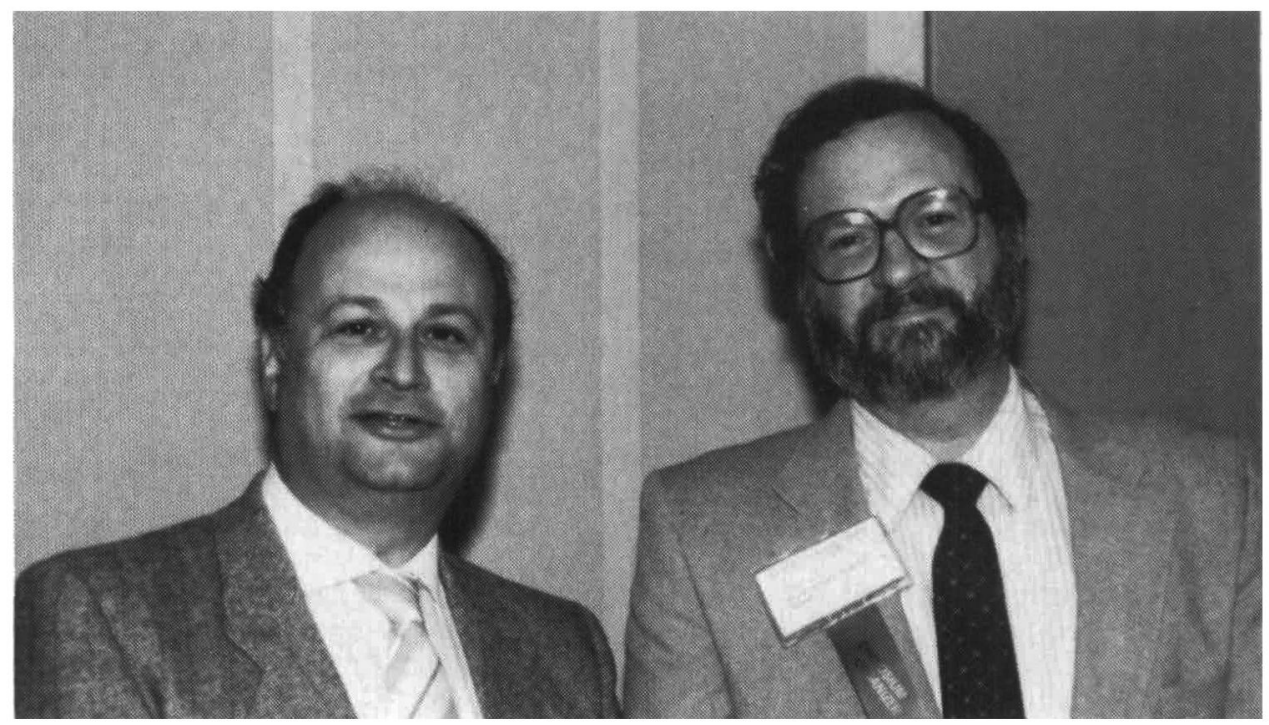

Symposium G Organizers (left to right): A. Kaldor and S. Riley.

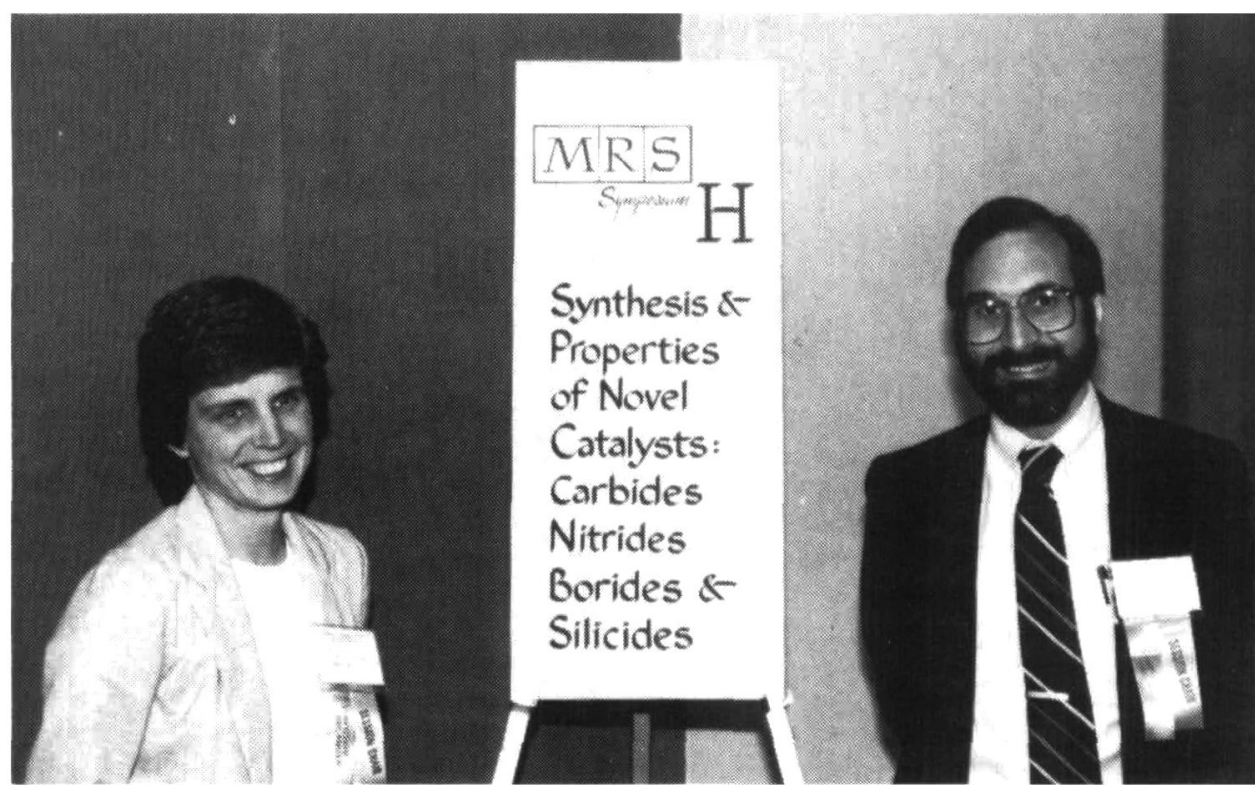

Symposium H Organizers (left to right): A.M. Stacy and J.N. Michaels. 
bides very efficient high temperature $p$ type thermoelectric materials. Beyond this application, interest was expressed in doping the wide-gap $(>3 \mathrm{eV})$ icosahedral boron-rich pnictides, $B_{12} P_{2}$ and $B_{12} A s_{2}$, for use as semiconductors. The papers at the symposium addressed the synthesis, structure as well as electronic and thermal properties of these materials.

Silicon carbides have several polytypes. Talks at this symposium primarily addressed $3 C$ (beta) silicon carbide. This material is thought to have advantageous semiconducting properties for integrated circuits. However, synthesis problems have been difficult to overcome. Presentations described methods of CVD growth of this material on a silicon substrate. Additionally, there were reports of attempts to characterize the nature of the donor and acceptor states. Characteristics of several types of devices were described.

The CVD synthesis of diamond films generated considerable excitement. It was shown how very dilute mixtures of methane in hydrogen can be deposited at relatively low temperatures $\left(500-1000^{\circ} \mathrm{C}\right)$ to yield diamond films. The large fraction of hydrogen in the gas mixture apparently plays an important role by inhibiting the formation of graphite. Roughening the silicon substrate and charging it positive was shown to greatly facilitate the deposition of diamond films. Devices made from diamond films were even reported.

The utilization of refractory semiconductors in thermoelectric power generation was extensively discussed. Rare earth chalcogenides based on the thorium phosphide structure received considerable attention as high temperature n-type thermoelectric elements.

Symposium Support: Air Force Office of Scientific Research; Office of Naval Research; Strategic Defense Initiative Organization, Innovative Science and Technology Office, Organized by JPL-ISTO; Elektroschmelzwerk Kempten $\mathrm{GmbH}$.

Proceedings: Volume 97 of the Materials Research Society Symposia Proceedings series.

\section{Geological Materials: Silicate Melts and Glasses (Symposium J)}

Symposium Organizers: Raymond Jeanloz (University of California), Gordon E. Brown, Jr. (Stanford University), and Hubert King (Exxon Research and Engineering).

Silicate melts and glasses are central to fields ranging from volcanology to fiber optics technology. This symposium concentrated on fundamental properties, providing a rare opportunity for physicists, chemists, and earth scientists to compare their most recent experimental and theoretical results on these materials.
Experiments covering an unprecedented range of pressure and temperature were described. For example, melt viscosity and compression have been measured to 3 and $40 \mathrm{GPa}$, respectively, whereas melting temperatures have been obtained to over 100 $\mathrm{GPa}$ (= 1 Megabar or $10^{6}$ atmospheres). Similarly, results were presented for $\mathrm{SiO}_{2}$ at temperatures as high as $10^{4} \mathrm{~K}$, corresponding to roughly $1 \mathrm{eV}$ of thermal excitation. The difficulty with these experiments is in observing melt properties while the sample is simultaneously at high pressures and high temperatures.

To complement the experimental measurements, the results of highly successful theoretical calculations were described. With the power in computing and graphics now available, it is possible to realistically simulate the structure and transport properties (e.g., diffusion and viscosity) of melts and glasses, despite the fact that the

bonding in silicates is complex (partly ionic, partly covalent) and that the noncrystalline systems exhibit complex atomic structures. That is, significant short- and medium-range order is present, and varies both with temperature and pressure. Nevertheless, relatively simple models reproduce many of the observed properties of silicate melts.

Among the highlights of the meeting were descriptions of two new types of glasses which are not formed by quenching a melt. The first, derived by sol-gel techniques, is relatively well known and provides important information on the nature of glass surfaces (thermodynamic energetics, vibrational properties, reactivity). The second type of athermal glass, however, is completely new. It is formed simply by compressing crystals under large pressures $\left(\sim 10^{10} \mathrm{~Pa}\right)$. Even at room temperature, this

Continued

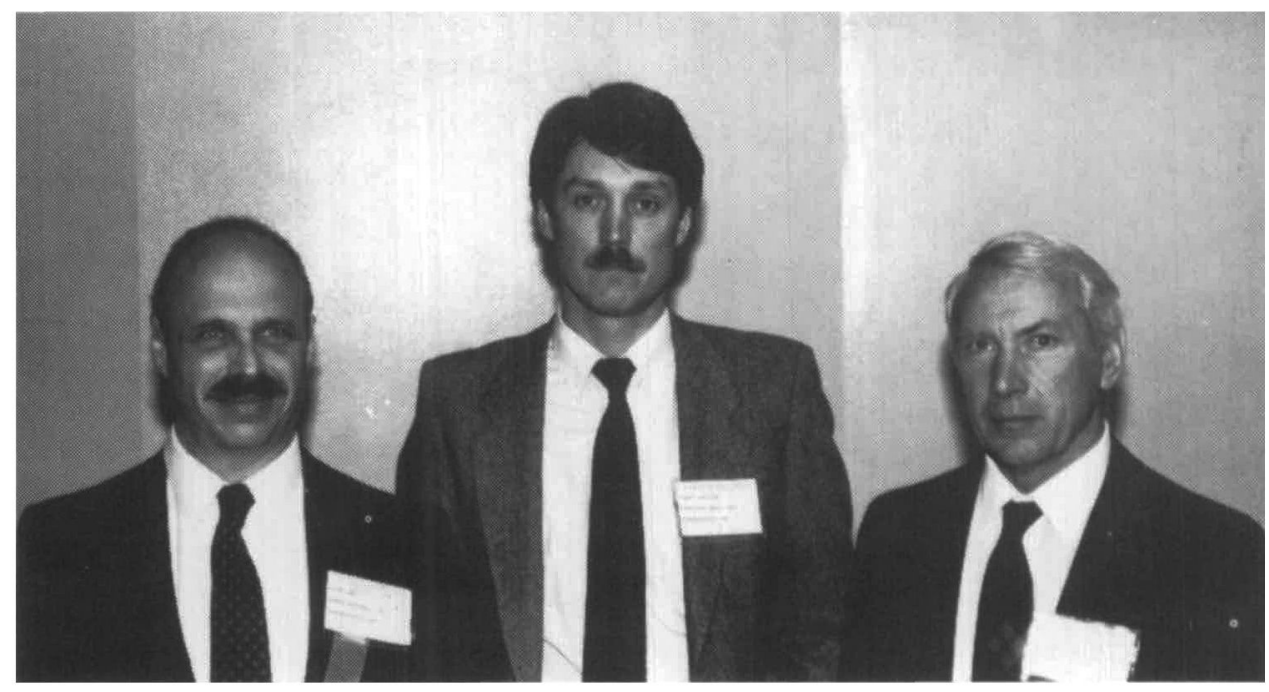

Symposium I Organizers (left to right): D. Emin, T.L. Aselage, and C. Wood.

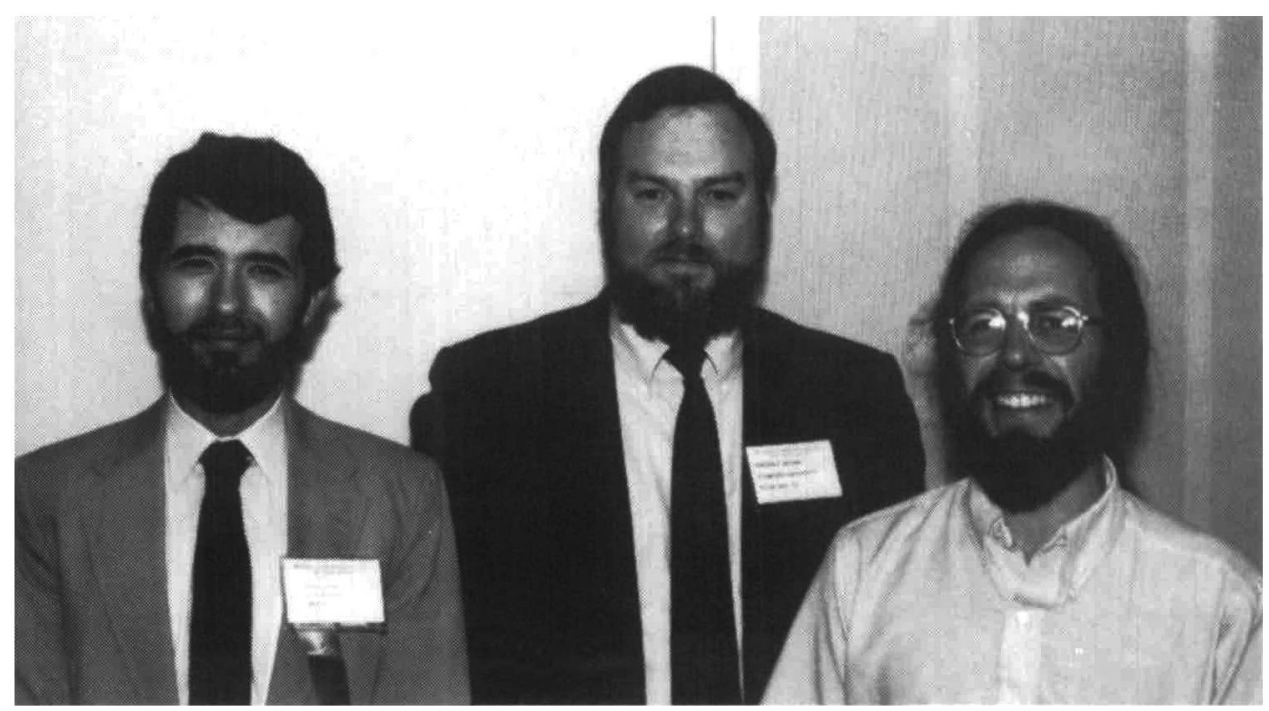

Symposium J Organizers (left to right): R. Jeanloz, G.E. Brown, Jr., and H. King. 
can result in highly densified glasses being formed. However, the microscopic mechanism involved in this amorphization is poorly understood.

With pressure, there is now good evidence that the structures of both melts and glasses can change drastically. The result for melts with complex coordination (like the silicates and a number of covalent systems) is that kinetic processes can be enhanced with pressure. These are among the rare cases in which an activation volume is negative. Similarly, it is surprising to find that silicate glasses can be made to undergo completely reversible coordination changes while at room temperature. At such low temperatures one would normally consider the kinetics for structural transformations to be prohibitively slow. Yet the consequence is that amorphous $\mathrm{SiO}_{2}$ actually becomes weaker with increasing pressure, over a range of tens of $\mathrm{GPa}$.

A final surprising result involves the study of low-temperature $(<100 \mathrm{~K})$ anomalies characteristically observed in glasses. These anomalies, for example, in specific heat, thermal conductivity, dielectric loss or acoustic loss, are found so reproducibly in glasses that they have been thought to be uniquely associated with amorphous structures. Now it appears that a few crystalline silicates with complex, feldspar structures also exhibit these "glass anomalies." As with the pressure-induced amorphization, the latest results suggest that there is a much closer link between silicate crystals and glasses than has previously been realized.

Symposium Support: Office of Naval Research, U.S. Army Research Office.

\section{High Temperature Superconductors over $\mathrm{T}_{\mathrm{c}}$ over $30 \mathrm{~K}$ (Symposium S) \\ Symposium Organizers: $M$. Schluter} (AT\&T Bell Laboratories) and D.U. Gubser (Naval Research Laboratory).

A special symposium on High Temperature Superconductors with $\mathrm{T}_{\mathrm{c}}$ over $30 \mathrm{~K}$ brought together most of the leading researchers working on the recently discovered superconducting oxide ceramics which promise to revolutionize many areas of technology. Plans for the symposium began in January, shortly after the impact of the discovery was realized. The discovery of still newer oxide superconductors with $\mathrm{T}_{c}$ over $90 \mathrm{~K}$ quickly made the title obsolete, but not the symposium. Originally 14 speakers were invited for a one-day symposium, but by the time of the conference, over 80 scientists from 8 different countries presented their work in a twoday meeting - the first day of which ran from 8:00 a.m. until after 12:00 midnight. The field is moving so fast that most titles of the talks were changed at the meeting.

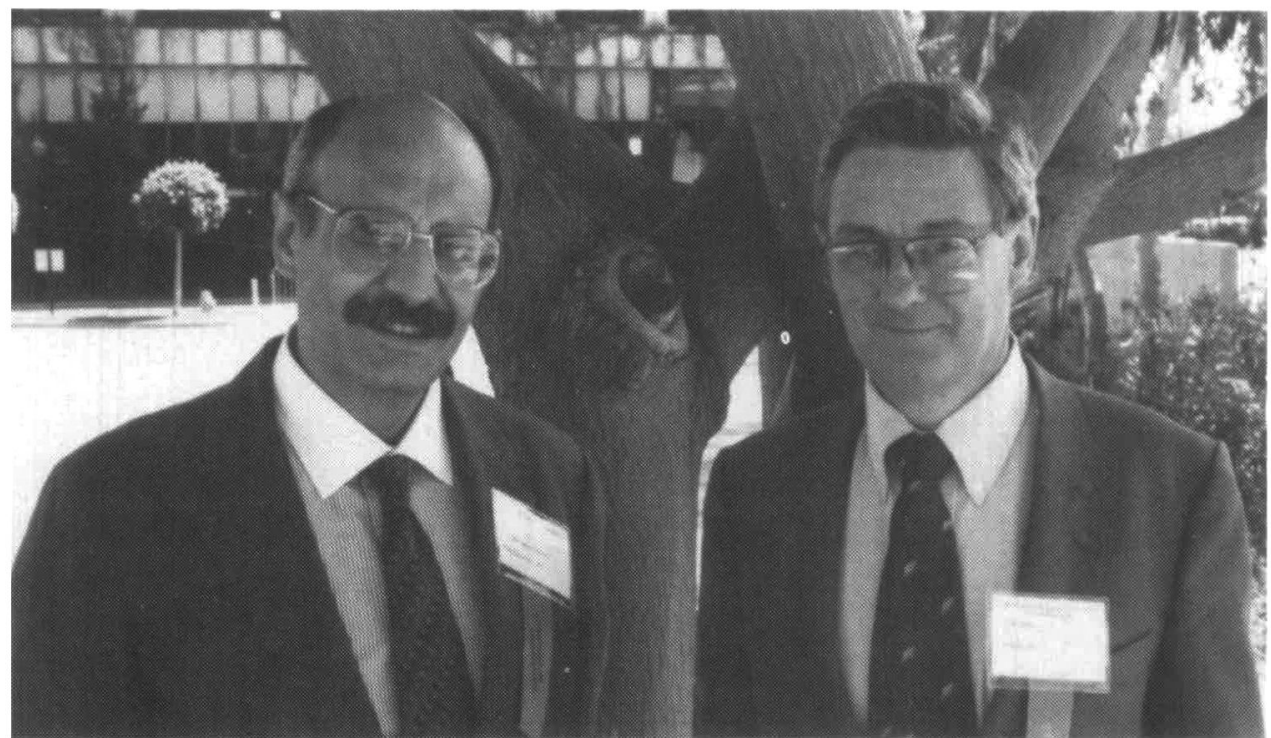

Symposium K Organizers (left to right): D. Apelian and J. Szekely.

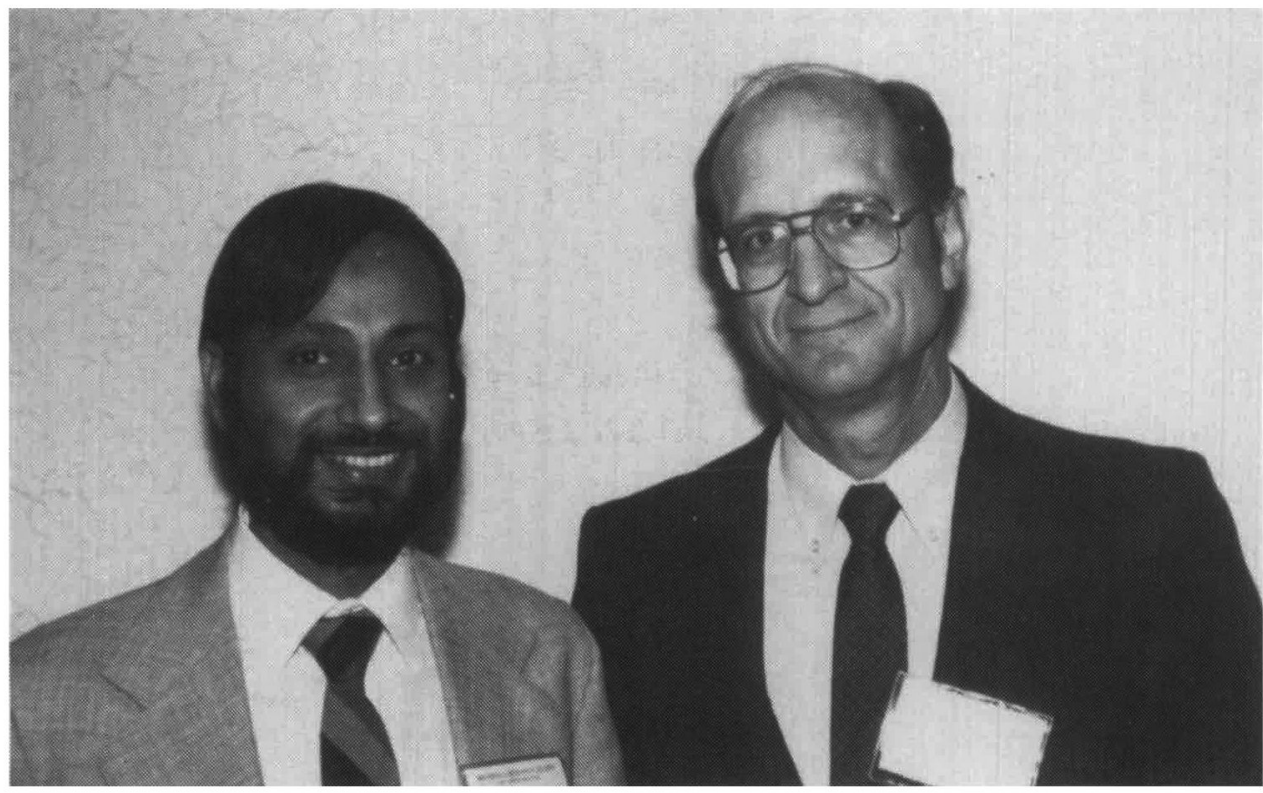

Symposium L Organizers (left to right): A. Madhukar and L. Leger.

This was the largest meeting yet held on the new superconducting materials and the extended abstracts will be the first collection of articles put together on the subject. The entire meeting has also been videotaped. An edited $\sim 7$ hour summary is available now from the Materials Research Society.

This MRS symposium was remarkably informative to all participants. From both the talks and the lively discussions that followed one could sense an openness to discuss the problems and the failures, not just the successes. There was a real information exchange and it was apparent that scientists were coming to grips with the fundamental issues in the field.

Many talks focused on the crystal structure details, which in the last few weeks have become more clear. Neutron scattering data and detailed Reitveld fitting procedures have located the atoms in the $\mathrm{Y}-\mathrm{Ba}-\mathrm{Cu}-\mathrm{O}$ compound which has a $\mathrm{T}_{\mathrm{c}}$ of 95 $K$. This structure has some very unusual features which undoubtedly contribute to its unusual properties. The copper and oxygen atoms form networks of both 1dimensional and 2-dimensional sublattices within the crystal. Many talks showed that the high superconducting transition temperatures are associated with the integrity of the 1-dimensional $\mathrm{Cu}-\mathrm{O}$ network. $\AA$ tetragonal-to-orthorhombic phase transition is associated with the disordering on the 1-dimensional $\mathrm{Cu}-\mathrm{O}$ chains. Several papers reported on this phase transition.

One of the more scientifically important

Continued 


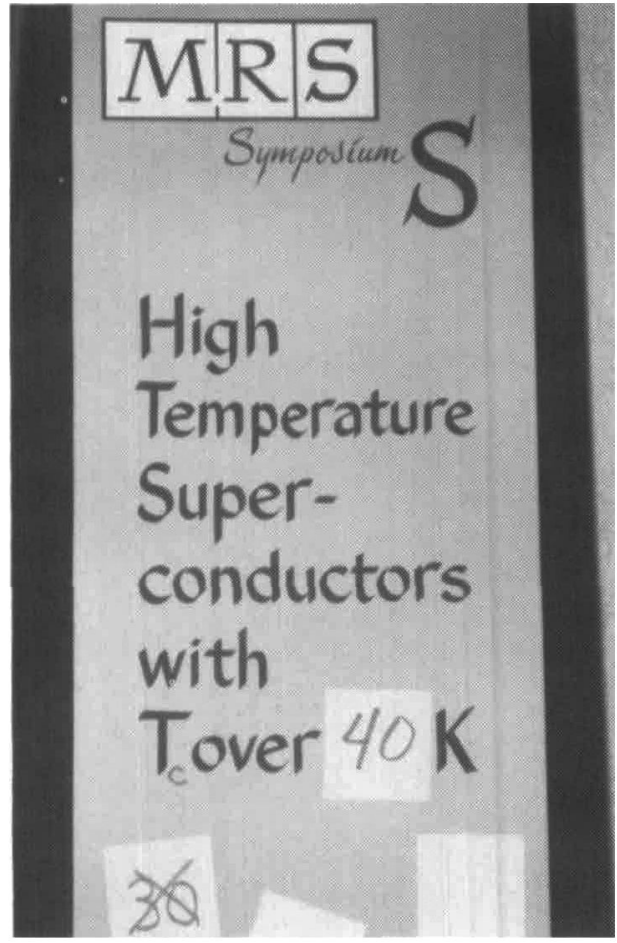

results reported at the symposium was on the isotope effect. Scientists at both AT\&T Bell Laboratories and Berkeley University reported that when $O(18)$ replaces $O(16)$ in the structure, no change in $T_{c}$ is observed. The standard BCS theory of superconductivity generally predicts a change in $T_{c}$ as the isotopic mass varies. Thus, this result suggests that a new mechanism producing superconductivity in these compounds may be operative.

Other significant results were reported: - Electron tunneling into single crystal $Y$ Ba-Cu-O compounds (IBM),

- Epitaxial growth of Y-Ba-Cu-O (NTT, Japan),

- New infrared absorption data which reported energy gaps closer to that reported from tunneling data (McMaster University, Canada),

- Experimental lattice vibrational spectrum as determined from inelastic neutron scattering (NRL \& NBS), and

- Antiferromagnetism in La-Cu-O (Exxon and AT\&T Bell Laboratories).

Throughout the meeting and the talks, much emphasis was devoted to material processing and microstructural characteristics. Details of annealing schedules were described and relations to both crystal and microstructure, as well as the physical properties, were discussed. Such details are very important both for understanding the basic mechanism of superconductivity in these compounds and for developing technology based on these materials.

The meeting was extremely beneficial to the scientists in the field. As many as 1,000 scientists attended the sessions, and at no time, even at 12:00 midnight on the first

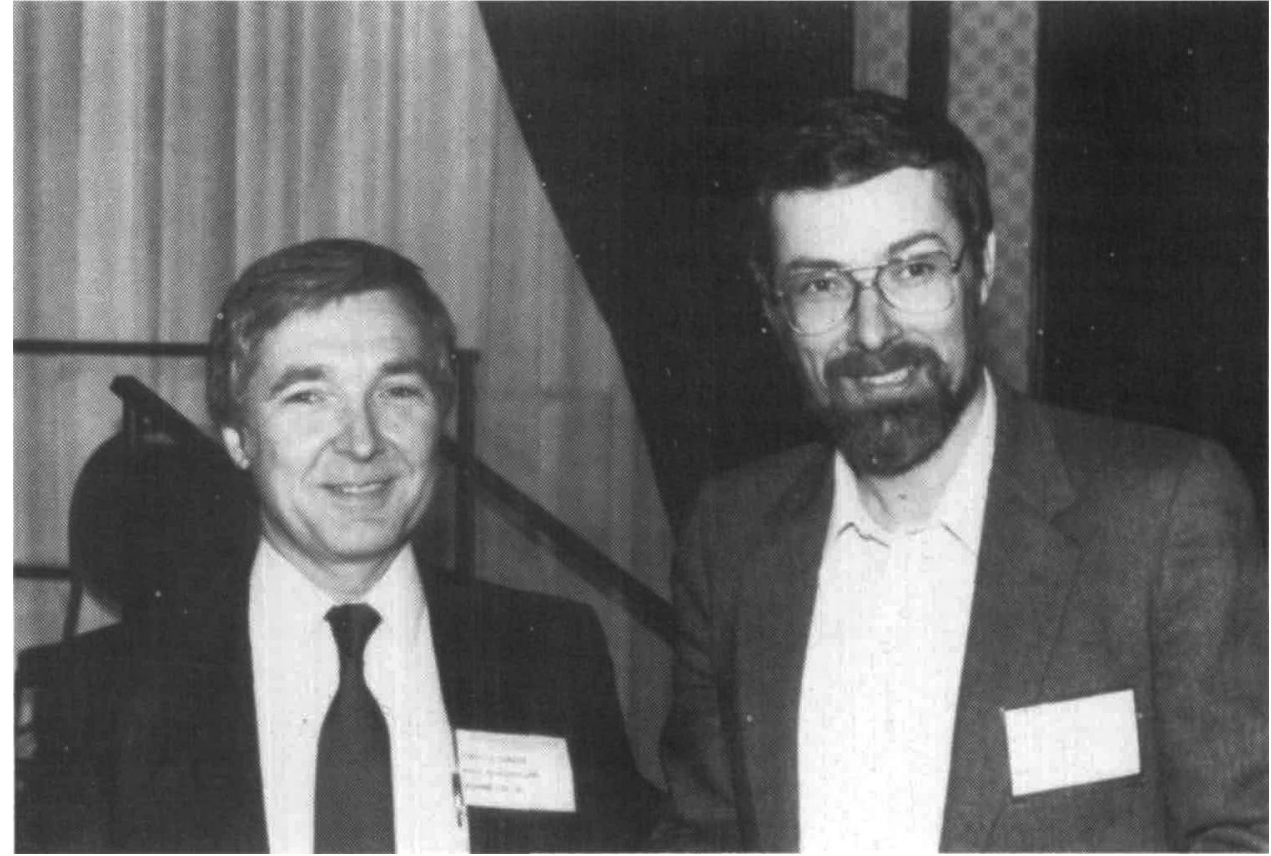

Symposium S Organizers (left to right): D.U. Gubser and M. Schluter. day or at 3:00 p.m. on the second day when the conference closed, were there less than 500 scientists in the audience.

Many questions remain, and much research needs to be done. Will there be new compounds found with still higher $T_{c}$ ? What must we do to obtain higher current carrying capacity in the materials and wires? How do we make quality thin films and multilayer structures? What is the un- derlying mechanism for producing the high $\mathrm{T}_{\mathrm{c}}$ ? How do we proceed to develop a technology based on the new materials? At the MRS symposium science began to emerge in this rapidly moving field, and answers to many of these questions can be expected soon.

Videotape (VHS or U-Matic) and Extended Abstract Volume EA-11 are available from the Materials Research Society.

\section{Graduate Student Awards 1987 MRS Spring Meeting}

Brent A. Detering, Department of Chemistry, University of Idaho, "Reduction of Selected Metal Oxides in a Thermal Plasma Produced by a Non-Transferred Arc Torch" (Symposium K)

Suliman A. Dregia, Metallurgical Engineering and Materials Science, Carnegie Mellon University, "Epitaxy for Weakly Interacting Systems of Large Misfit" (Symposium D)

Tony E. Haynes, Department of Physics and Astronomy, University of North Carolina, "Effects of $\mathrm{Ga}$ and As Evaporation on Properties of $\mathrm{TaSi}_{2}$-GaAs Schottky Barriers" (Symposium B)

Dusit Kruangam, Department of Electrical Engineering, Osaka University, "Amorphous Silicon-Carbide Multilayered Visible-Light Emitting Diode" (Symposium E)

Mark A. Petrich, Department of Chemical Engineering, University of California, "Local Bonding Arrangements in Amorphous Silicon Alloys" (Symposium E)

R. Ramesh, Materials Science, University of California, "Effect of Heavy Rare Earth Additions on Microstructure and Magnetic Properties of Fe-Nd-B Magnets" (Symposium F) 